\title{
Penerapan Strategi Heuristik Vee dengan Media Games ROTANKUS Terhadap Hasil Belajar Trigonometri Siswa
}

\author{
Fatimah \\ Prodi Pendidikan Matematika, Universitas Al Asyariah Mandar, fatimah@mail.unasman.ac.id
}

Febryanti

Prodi Pendidikan Matematika, Universitas Al Asyariah Mandar

Yako

Mahasiswa Prodi Pendidikan Matematika, Universitas Al Asyariah Mandar

\begin{abstract}
ABSTRAK, ROTANKUS singkatan dari Roda Putar dan Kartu Undian Soal, merupakan salah media yang digunakan dalam pembelajaran matematika materi trigonometri. Penelitian ini bertujuan untuk mengetahui pengaruh penerapan Strategi Heuristik Vee dengan media games ROTANKUS terhadap hasil belajar Trigonometri siswa. Desain Penelitian yang digunakan adalah Quasi Eksperimental dengan populasi sebanyak 359 orang kelas $X$ SMA Negeri 1 Polewali yang sampelnya adalah siswa kelas X IPS 1 yang berjumlah 35 sebagai kelas kontrol dan siswa kelas X IPS 3 berjumlah 36 orang sebagai kelas eksperimen. Instrumen penelitian berupa tes hasil belajar, lembar aktifitas siswa dan lembar obsevasi keterlaksanaan pembelajaran. Data yang terkumpul dianalisis dengan menggunakan teknik statistik deskriptif dan statistik Inferensial. Hasil analisis deskriptif pada kelas eksperimen menunjukkan bahwa nilai rata-rata pre-test adalah 52,92, setelah diberi perlakuan penerapan strategi heuristik vee dengan media games rotankus diperoleh nilai rata-rata postes 78,67, sedangkan pada kelas kontrol nilai rata-rata pretest adalah 49,86 dan pos-test adalah 67,43. Hasil Inferensial untuk uji Normalitas kedua kelompok data yaitu berdistribusi normal dan berasal dari populasi yang homogen. Berdasarkan hasil uji Hipotesis diperoleh nilai sig $0,000<0,05$ sehingga $H_{0}$ ditolak dan $H_{1}$ diterima yang berarti bahwa ada perbedaan antara hasil belajar siswa yang diajar dengan menggunakan strategi heuristik vee dengan media games ROTANKUS dan tanpa menggunakan strategi heuristik vee dengan media games ROTANKUS,sehingga dapat disimpulkan bahwa penerapan strategi heuristik vee dengan media games ROTANKUS berpengaruh terhadap hasil belajar Trigonometri siswa kelas X SMA Negeri 1 Polewali.
\end{abstract}

Kata Kunci:Pengaruh, Strategi Heuristik Vee, media games, Rotankus dan Hasil Belajar

\section{PENDAHULUAN}

Perkembangan dunia pendidikan saat ini menjadi persoalan umat manusia dan bangsa manapun. Pendidkan sangat berperan terhadap kemajuan peradaban suatu bangsa. Jika pendidikan pada suatu bangsa mengalami kemorosotan, maka secara signifikan akan menyebabkan kemerosotan pada bidang lain sampai pada kemajuan suatu negara. Kemorosotan dalam bidang pendidikan tersebut salah satu penyebabnya adalah terdapatnya masalah dalam pendidikan khususnya pendidikan Matematika, karena Matematika merupakan ratu dari semua ilmu pengetahuan artinya matematika tidak bergantung pada ilmu lain dan sekaligus pelayan dalam ilmu pengetahuan. [1],[2]. Hal inilah yang merupakan salah satu alasan untuk mereformasi pendidikan Matematika disekolah.

Berdasarkan hasil Observasi yang telah dilakukan dikelas X IPS 3 terdapat beberapa siswa yang dapat menangkap pembelajaran yang diberikan oleh Guru secara langsung dan ada pula siswa hanya duduk diam tanpa memperhatikan penjelasan dari guru dan sebagian dari siswa mengantuk atau jenuh dikarenakan pembelajaran matematika yang berlangsung pada jam terakhir, hal ini menyebabkan rendahnya hasil belajar siswa, olehnya itu diperlukan strategi pembelajaran dapat mengaktifkan siswa dan meningkatkan hasil belajarnya.

Salah satu strategi yang dapat diterapkan adalah strategi Heuristik Vee dengan media games ROTANKUS. Strategi pembelajaran Heuristik Vee adalah strategi pembelajaran yang di rancang pada suatu permasalahan atau objek yang memberikan penjelasan bahwa pengetahuan baru dapat dikonstruksi melalui penyelesaian dari sebuah permasalahan yang berkaitan dengan pengetahuan berikutnya, sedangkan Heuristik sendiri merupakan suatu penuntun dalam bentuk pertayaan atau perintah yang berfungsi mengarahkan dalam pemecahan masalah. 
Strategi Heuristik Vee dengan media games ROTANKUS agar suasana belajar dari pasif keaktif dari kaku menjadi gerak (akrab), dari jenuh menjadi riang. Media ini diarahkan agar tujuan belajar dapat dicapai secara efisien dan efektif dalam suasana gembira meskipun membahas hal-hal yang sulit dan berat.

Heuristik berasal dari bahasa yunani, yaitu heuriskein yang berarti "saya menemukan". Dalam perkembangannya, strategi ini berkembang menjadi sebuah strategi pembelajaran yang menekankan pada aktivitas peserta didik dalam memahami materi pembelajaran dengan menjadikan heuriskein sebagai acuan. Strategi pembelajaran ini berbasis pada pengolahan pesan atau pemprosesan informasi yang dilakukan peserta didik sehingga memperoleh pengetahuan, keterampilan dan nilai-nilai. Strategi ini berasumsi bahwa kegiatan pembelajaran haruslah dapat menstimulus peserta didik agar aktif dalam proses pembelajaran, seperti memahami materi pelajaran, bisa merumuskan masalah, menetapkan hipotesis, mencari fakta dan memecahkan masalah.

Berdasarkan uraian sebelumnya, maka permasalahan yang akan di bahas dalam tulisan ini adalah: "Bagaimanakah pengaruh penerapan strategi heuristik vee dengan media games ROTANKUS terhadap hasil belajar Trigonometri siswa kelas X SMA Negeri 1 Polewali?".

\section{TINJAUAN PUSTAKA}

Strategi pembelajaran Heuristik vee adalah strategi pembelajaran yang di rancang pada suatu permasalahan atau objek yang memberikan penjelasan bahwa pengetahuan baru dapat dikonstruksi melalui penyelesaian dari sebuah permasalahan yang berkaitan dengan pengetahuan berikutnya, sedangkan Heuristik sendiri merupakan suatu penuntun dalam bentuk pertayaan atau perintah yang berfungsi mengarahkan dalam pemecahan masalah. Heuristik Vee merupakan strategi pembelajaran yang digunakan untuk menyelesaikan masalah dan memahami pengetahuan.
Dalam Kamus Bahasa Indonesia kata "roda adalah barang bundar (berlingkar dan biasanya berjeruji)" jadi roda adalah obyek berbentuk bundar atau lingkaran.sedangkan dalam Kamus Bahasa Indonesia "putar mempunyai definisi gerakan berpusing atau berputar, berganti arah, berbelok jadi putar adalah gerakan berkeliling atau berganti arah. Dengan kata lain roda putar adalah obyek berbentuk bundar atau lingkaran yang dapat diputar.

Media roda putar adalah media permainan berupa roda atau lingkaran yang terbagi menjadi beberapa sektor atau bagian yang didalamnya terdapat pertanyaan-pertanyaan [3]. Dalam penggunaannya, media ini dapat menarik perhatian belajar, membuat siswa lebih aktif serta proses pembelajaran dapat berlangsung secara menyenangkan.

Kartu soal merupakan sebuah kartu yang berisi soal yang dibuat menarik dengan menggunakan kertas yang menarik [4]. Kartu yang berisi soal-soal yang harus dijawab oleh siswa. Dengan adanya kartu soal, siswa dilatih untuk mengerjakan latihan soal sambil berdiskusi dengan kelompoknya, sehingga dapat meningkatkan pemahaman siswa tentang materi yang disajikan oleh guru [5]. Kartu soal dapat dibuat warna warni yang kemuadian diberikan kepada siswa untuk diisi bersama kelompoknya yang sudah ditentukan.

Games ROTANKUS (Roda Putar dan Kartu Undian Soal) dalam permainan ini siswa dibagi menjadi beberapa kelompok dan setiap perwakilan kelompok melakukan 1 kali putaran pada roda putar, setelah selesai melakukan putaran maka siswa mengambil kartu undian soal sesuai warna yang ditunjuk oleh putaran tersebut, setelah semua perwakilan kelompok mengambil kartu undian soal tersebut maka semua perwakilan kelompok kembali ke masing-masing kelompok tanpa membuka kartu undian soal,sebelum ada aba-aba. Setelah itu peneliti mempersiapkan waktu dan memberikan aba-aba untuk membuka kartu undian soal dan semua kelompok serentak membuka kartu undian soal tersebut. 


\section{METODOLOGI}

Penelitian ini merupakan penelitian eksperimen yang melibatkan dua kelas yang dikenakan dua perlakuan yang berbeda, berupa pembelajaran matematika dengan menggunakan strategi heuristik vee dengan media games ROTANKUS (kelas eksperimen) dan pembelajaran matematika tanpa menggunakan strategi heuristik vee dengan media games ROTANKUS (kelas kontrol).

Desain penelitian yang digunakan adalah penelitian eksperimen semu (quasi experimental) dengan melibatkan dua kelompok kelas yang diambil secara utuh. Kedua kelompok kelas kemudian dibedakan menjadi satu kelas sebagai kelompok Eksperimen dan satu kelas sebagai kelompok Kontrol. Model desain yang digunakan sebagai berikut:

Tabel 1: Desain Penelitian

\begin{tabular}{|c|c|c|}
\hline$O_{1}$ & $\mathrm{X}$ & $\mathrm{O}_{2}$ \\
\hline$O_{3}$ & $\mathrm{C}$ & $\mathrm{O}_{4}$ \\
\hline
\end{tabular}

Sumber: Tiro $(2014: 27)$

Keterangan:

$o_{1}:$ Pemberian test awal kelompok eksperimen

$o_{3}$ : Pemberian test awal kelompok kontrol

$X$ : Eksperimen

$C$ : Kontrol

$\mathrm{O}_{2}$ : Pemberian tes akhir kelompok eksperimen

$o_{4}$ : Pemberian tes akhir kelompok kontrol

Pengumpulan data yang dilakukan dalam penelitian melalui:

a. Pemberian Tes hasil belajar Trigonometri.

Tes adalah alat prosedur yang digunakan untuk mengetahui atau mengukur Hasil Belajar Geometri Siswa, yang terdiri dari

1) Pretest diberikan di awal pertemuan sebelum proses belajar mengajar dimulai untuk mengetahui kemampuan awal (hasil belajar) Trigonometri siswa.

2) Post test diberikan di akhir pembelejaran, setelah diberikan perlakuan untuk mendapatkan data akhir hasil belajar Trigonometri siswa

b. Lembar observasi

1) Lembar Obsevasi Aktivitas Siswa
Lembar obsevasi aktivitas siswa digunakan untuk mengamati aktivitas siswa selama proses belajar mengajar dikelas kontrol dan eksperimen SMA Negeri 1 Polewali.

2) Lembar Observasi keterlaksanaan pembelajaran

Observasi dilakukan untuk mengamati keterlaksanaan pembelajaran yang dilakukan oleh pengajar selama proses mengajar dikelas baik yang menerapkan straregi Heuristik Vee dengan media Rotankus di kelas eksprimen, maupun yang tidak menerapkan straregi Heuristik Vee dengan media Rotankus.

Untuk menganalisis data hasil penelitian, maka digunakan teknik analisis statistik deskriptif dan analisis statistik inferensial. Analisis statistik deskriptif digunakan untuk mendeskripsikan data dari masing-masing kelompok responden berupa distribusi frekuensi, rataan (mean), rentang (range), nilai maksimum dan minimum, median, simpangan baku, dan kategori hasil belajar.

Analisis statistik inferensial digunakan untuk menguji hipotesis penelitian sebelum dilakukan pengujian, maka terlebih dahulu dilakukan pengujian prasyarat yaitu uji normalitas, uji homogenitas.

\section{PEMBAHASAN}

\section{Analisis Statistik Deskriptif}

Data hasil belajar Trigonometri siswa pada pre test dan post tes di kelas X IPS 3 (kelas eksperimen) dan kelas X IPS 1(kelas kontrol) SMA Negeri 1 Polewali.

Tabel 4.1 Analisis Statistik deskriptif hasil belajar awal (pre-test) Trigonometri siswa

\begin{tabular}{|c|c|c|c|}
\hline & & $\begin{array}{c}\text { Kelas } \\
\text { Eksperimen }\end{array}$ & $\begin{array}{c}\text { Kelas } \\
\text { Kontrol }\end{array}$ \\
\hline \multirow[t]{2}{*}{$\mathrm{N}$} & Valid & 36 & 35 \\
\hline & Missing & 0 & 0 \\
\hline \multicolumn{2}{|c|}{ Mean } & 52.92 & 49.86 \\
\hline \multicolumn{2}{|c|}{ Median } & 55.00 & 50.00 \\
\hline \multicolumn{2}{|c|}{ Mode } & 70 & 60 \\
\hline \multicolumn{2}{|c|}{ Stdr. Deviation } & 20.262 & 20.775 \\
\hline
\end{tabular}




\begin{tabular}{lrr}
\cline { 2 - 3 } & \multicolumn{1}{c}{ Kelas } & \multicolumn{1}{c}{ Kelas } \\
Eksperimen & \multicolumn{1}{c}{ Kontrol } \\
\hline Variance & 410.536 & 431.597 \\
Range & 80 & 80 \\
Minimum & 0 & 0 \\
Maximum & 80 & 80 \\
Sum & 1905 & 1745 \\
\hline
\end{tabular}

Tabel 4.1 menunjukkan bahwa nilai rata-rata hasil belajar Trigonometri siswa pada pre-test di kelas eksperimen dan kontrol cendrung sama. Begitu juga dengan sebaran data lainnya seperti range dan variasi data.

Sajikan data skor hasil belajar trigonometri siswa berdasarkan Kriteria Ketuntasan Minimal (KKM) pelajaran Matematika yang berlaku di SMA Negeri 1 Polewali yaitu 70.

Tabel 4.2 KKM Hasil Belajar Siswa Trigonometri Siswa Pada Pre-Tes

\begin{tabular}{|c|c|c|c|c|c|}
\hline Nilai & Kriteria & \multicolumn{2}{|c|}{ Eksperimen } & \multicolumn{2}{c|}{ Kontrol } \\
\cline { 3 - 6 } & & $\mathrm{F}$ & $\%$ & $\mathrm{~F}$ & $\%$ \\
\hline $0 \leq \mathrm{N}<70$ & Tidak & 24 & 66,67 & 26 & 74,86 \\
& Tuntas & & & & \\
\hline $70 \leq \mathrm{N} \leq 100$ & Tuntas & 12 & 33,33 & 9 & 25,14 \\
\hline
\end{tabular}

Tabel 4.2 menggambarkan bahwa secara kuantitas jumlah siswa yang tuntas maupun tidak tuntas pada kedua kelas tidak berbeda jauh. Jumlah siswa tuntas pada pre test di kelas ekprimen 24 sedangkan pada kelas kontrol 26, sehingga masih dapat disimpulkan kemampuan awal siswa pada kedua kelas cenderung sama.

Tabel 4.3 Analisis Statistik deskriptif hasil belajar Trigonometri siswa pada post-test

\begin{tabular}{lrr}
\hline & \multicolumn{2}{c}{$\begin{array}{c}\text { Kelas } \\
\text { Eksperimen }\end{array}$} \\
& \multicolumn{2}{c}{ Kontrol } \\
\hline $\mathrm{N} \quad$ Valid & 36 & 35 \\
\multicolumn{1}{c}{ Missing } & 0 & 0 \\
\hline Mean & 78.67 & 67.43 \\
Median & 78.00 & 68.00 \\
Mode & 84 & $64^{\mathrm{a}}$ \\
Std. Deviation & 9.891 & 7.461 \\
Variance & 97.829 & 55.664 \\
Range & 36 & 24 \\
\hline
\end{tabular}

\begin{tabular}{lrr}
\hline & \multicolumn{1}{c}{ Kelas } \\
Eksperimen & \multicolumn{1}{c}{ Kelas } \\
& 60 & 56 \\
Minimum & 96 & 80 \\
Maximum & 2832 & 2360 \\
Sum & &
\end{tabular}

Tabel 4.3 menunjukkan bahwa nilai rata-rata hasil belajar trigonometri siswa pada pos-test di kelas eksperimen lebih tinggi (78.67) dari kontrol $(67,43)$.

Tabel 4.4 KKM Hasil Belajar Siswa Trigonometri Siswa Pada pos-tes

\begin{tabular}{cc|cccc}
\hline Nilai & Kriteria & \multicolumn{2}{c}{ Eksperimen } & \multicolumn{2}{c}{ Kontrol } \\
\cline { 3 - 6 } & & F & $\%$ & F & $\%$ \\
\hline $0 \leq \mathrm{N}<70$ & Tidak & 9 & 25 & 21 & 60 \\
& $\begin{array}{c}\text { Tuntas } \\
70 \leq \mathrm{N} \leq 100\end{array}$ & & & & \\
& Tuntas & 27 & 75 & 14 & 40 \\
\hline
\end{tabular}

Tabel 4.4 menggambarkan bahwa secara kuantitas jumlah siswa yang tuntas pada post-test di kelas eksprimen lebih tinggi (15 orang) dibandingkan pada kelas kontrol (5 orang).

Berdasarkan hasil analisis destkriptif data hasil belajar Trigonometri siswa baik pada pre test maupun post test menunjukkan bahwa nilai trigonometri siswa pada kelas yang menerapkan strategi heuristik vee dengan media games Rotankus lebih baik dari kelas yang tidak menerapkan strategi heuristik vee dengan media games Rotankus.

Hal ini sejalan dengan penelitan yang dilakunan oleh [6] yang menyimpulkan bahwa kemampuan pemecahan masalah matematika siswa yang diajar berbantuan kartu soal lebih baik dari kelas yang diajar tanpa menggunakan kartu soal. Begitupun penelitian yang dilakukan [7] yang menyimpulkan bahwa pembelajaran dengan menggunakan media kartu pintar dan kartu soal efektif untuk meningkatkan prestasi belajar siswa.

\section{Analisis statistik inferensial}

Analisis statistik inferensial digunakan untuk pengujian hipotesis penelitian. Uji hipotesis yang digunakan dalam penelitian ini adalah uji-t (t-test) untuk menguji signifikan perbedaan rata-rata (mean) antara kelompok data 
dari nilai hasil belajar Trigonometri siswa yang dicapai siswa pada tes awal (pre-test) dan pada tes akhir (pos-test) untuk masing masing kelas yaitu kelas X IPS 3 (kelas eksperimen) dan kelas X IPS 1 (kelas kontrol). Pada pengujian hipotesis penelitian digunakan taraf signifikan $95 \%, \alpha=$ 0,05 .

Sebelum melakukan analisis inferensial terlebih dahulu dilakukan uji prasyarat analisis, yaitu uji normalitas data dan uji homogenitas dua kelompok data.

Tabel 4.5 Uji Normalitas data Nilai Pre-test Kelas X IPS 3 (kelas eksperimen) dan Kelas X IPS 1 (kelas kontrol) SMA Negeri 1 Polewali

\begin{tabular}{lrcr}
\hline & \multicolumn{3}{c}{ Kolmogorov-Smirnov } \\
\cline { 2 - 4 } & Statistic & Df & \multicolumn{1}{c}{ Sig. } \\
\hline Eksperimen & 0.141 & 36 & 0.067 \\
Kontrol & 0.144 & 35 & 0.062 \\
\hline
\end{tabular}

Berdasarkan tabel 4.5, Test Of Normality pada kolom Kolmogrov-Smirnov, dari tabel terlihat bahwa nilai signifikansi untuk pre-test kelas eksperimen adalah $0.067>0,05$ dan untuk pretest kelas kontrol adalah $0.062>0,05$. Maka dapat disimpulkan bahwa data pada pre-test eksperimen dan pre-test kontrol berdistribusi normal

Tabel 4.6 Uji Homogenitas data Nilai Pre-test Kelas X IPS 3 (kelas eksperimen) dan kelas X IPS 1 (kelas kontrol)

\begin{tabular}{rrrrr}
\hline Levene Statistic & df1 & df2 & Sig. & \\
\hline 0.054 & 1 & 69 & 0.817 \\
\hline
\end{tabular}

Berdasarkan hasil uji homogenitas varians dengan menggunakan uji Levene pada tabel 4.6, diperoleh nilai signifikansi adalah $0.817>0.05$ maka dapat disimpulkan bahwa peserta didik kelas kontrol dan kelas eksperimen berasal dari populasi-populasi yang mempunyai varians yang sama, atau kedua kelas tersebut homogen.

Tabel 4.7 Uji Normalitas Data Nilai Pos-test Kelas X IPS 3 (kelas eksperimen) dan Kelas X IPS 1 (kelas kontrol)

\begin{tabular}{crrr} 
& \multicolumn{3}{c}{ Kolmogorov-Smirnov } \\
\cline { 2 - 4 } & Statistic & Df & \multicolumn{1}{c}{ Sig. } \\
\hline Eksperimen & 0.122 & 36 & 0.197
\end{tabular}

\begin{tabular}{llll} 
Kontrol & 0.134 & 35 & 0.112 \\
\hline
\end{tabular}

Tabel 4.7 menunjukkan bahwa bahwa nilai signifikansi untuk pos-test kelas eksperimen adalah $0.197>0,05$ dan postes kelas kontrol adalah $0.112>0,05$. Hal ini berarti bahwa data post-test pada kelas eksperimen dan kelas kontrol berdistribusi normal

Tabel 4.8 Uji Homogenitas data Hasil Belajar post-test kelas eksperimen dan kelas kontrol

\begin{tabular}{cccc} 
Levene Statistic & df1 & df2 & Sig. \\
\hline 2.951 & 1 & 69 & 0.090 \\
\hline
\end{tabular}

Tabel 4.8 menunjukkan bahwa dengan menggunakan Test of Homogeneity of Variance diperoleh hasil hitung untuk nilai sig $>\alpha$ yaitu $0,090>0,05$. Sehingga dapat disimpulkan bahwa kedua data tersebut berasal dari populasi yang sama/ variansi data homogen.

Berdasarkan hasil analisis data hasil postest kedua kelompok data diperoleh nilai signifikansi $0,000<0,05$ maka $H_{0}$ ditolak dan $H_{1}$ diterima yaitu secara signifikan nilai rata-rata skor hasil belajar Trigonometri kelas eksperimen, yang menggunakan strategi heuristik vee dengan media games ROTANKUS tidak sama dengan skor rata-rata hasil belajar Trigonometri siswa kelas kontrol yang diajar tanpa menggunakan strategi heuristik vee dengan media games ROTANKUS. Ini berarti bahwa terdapat pengaruh strategi heuristik vee dengan media games ROTANKUS terhadap hasil belajar Trigonometri siswa. Hal ini sejalan dengan penelitian yang dilakukan oleh [8], [9] yang menyatakan bahwa hasil pembelajaran dengan strategi heuristik lebih baik daripada pendekatan konvensional terhadap kemampuan siswa dalam memecahkan masalah matematika siswa. Sejalan degan itu [10] menyatakan bahwa mahasiswa yang diajar dengan strategi pembelajaran heuristik vee memiliki kemampuan pemahaman konsep lebih tinggi dari pada matematika mahasiswa yang diajar dengan strategi pembelajaran konvensional 


\section{KESIMPULAN}

Berdasarkan hasil analsisi Hasil penelitian yang telah dilakukan di kelas eksperimen dengan menggunakan strategi heuristik vee dengan media games ROTANKUS lebih tinggi dibandingkan dengan hasil belajar kelas kontrol yang tanpa menggunakan strategi heuristik vee dengan media games ROTANKUS dengan pokok bahasan yang sama yaitu Trigonometri. Hal ini dapat dilihat dari hasil analisis deskriptif pada kelas eksperimen lebih tinggi daripada kelas kontrol. Sedangkan untuk kriteria ketuntasan untuk kelas eksperimen lebih tinggi daripada kelas kontrol. Untuk hasil analisis inferensial dimana data skor hasil pre test dan post tes pada kelas eksperimen dan kelas kontrol keduanya berdistribusi normal dan memiliki variansi yang homogeny. Hal ini menunjukkan bahwa pembelajaran dengan strategi heuristik vee dengan media games ROTANKUS lebih berpengaruh positif dalam hasil belajar Trigonometri siswa kelas X SMA Negeri 1 Polewali dengan kata lain $H_{1}$ diterima.

\section{DAFTAR PUSTAKA}

[1] Nadeak, L. A. Analisis Kesulitan Pemecahan Masalah Siswa Tipe Kepribadian Introvert Dalam Menyelesaikan Soal Matematika Bentuk Cerita Di Kelas VIII SMP. Universitas Jambi.

[2] Sulistiani, E., \& Masrukan, M. 2017. Pentingnya berpikir kritis dalam pembelajaran matematika untuk menghadapi tantangan MEA. In PRISMA, Prosiding Seminar Nasional Matematika (pp. 605-612).

[3] Khairunnisa, wardah. (2017). "Pengembangan Media Permainan Roda Putar Berbasis Website untuk Keterampilan Membaca Bahasa Prancis Siswa Kelas XI SMA Angkas Adisutjiptu.skripsi. Yogyakarta....mau cari referensi lain

[4] Faizah, Ngaidatum. (2009). Model Pembelajaran Kooperatif Tipe TGT dengan Menggunakan Poster dan Media
Kartu Soal untuk Meningkatkan Minat dan Hasil Belajar Fisika. Skiprsi. Semarang.

[5] Qurniawati, A., \& Saputro, A. N. C. (2013). Efektivitas metode pembelajaran kooperatif tipe numbered head together (nht) dengan media kartu pintar dan kartu soal terhadap prestasi belajar siswa pada materi pokok hidrokarbon kelas $x$ semester genap SMA Negeri 8 surakarta. Jurnal Pendidikan Kimia, 2(3), 166-174.

[6] Sari, Titin Indah. 2014. Penerapan Model Pembelajaran Kooperatif Tipe Student Favilitator And Explaining Berbantuan Kartu Soal Terhadap Kemampuan Pemecahan Masalah Matematika Siswa Kelas Viii Smp Negeri 2 Ulujami. Jurnal $\delta$ E L T $\Delta$, Vol.2 No.2, Juli 2014, hlm 7-17

[7] Qurniawati, A., Sugiharto, Saputro, A.N.C. 2013. Efektivitas Metode Pembelajaran Kooperatif Tipe Numbered Head Together (Nht) Dengan Media Kartu Pintar Dan Kartu Soal Terhadap Prestasi Belajar Siswa Pada Materi Pokok Hidrokarbon Kelas X Semester Genap Sma Negeri 8 Surakarta Tahun Pelajaran 2012/2013. Jurnal Pendidikan Kimia (JPK), Vol. 2 No. 3 Tahun 2013 Program Studi Pendidikan Kimia Universitas Sebelas Maret

[8] Tambunan, H. (2020). Kemampuan Siswa dalam Pemecahan Masalah Matematika dengan Strategi Heuristik. Sepren, 1(02), 28-33.

[9] Pramita, D., \& Rusmayadi, M. 2018. Pengaruh Strategi Heuristik Pada Pendekatan Pemecahan Masalah Dalam Pembelajaran Matematika Kelas VIII SMP.JTAM (Jurnal Teori dan Aplikasi Matematika), 2(2), 157-161.

[10] Suhyanto, O., \& Musyrifah, E. 2016. Pengaruh Strategi Heuristik Vee Terhadap Kemampuan Pemahaman Konsep Matematik. FIBONACCI: Jurnal Pendidikan Matematika Dan Matematika. https://doi.org/10.24853/fbc.2.2.40-57 